\title{
Educação Ambiental (EA) em espaços não formais de educação: a potencialidade da Escola Bíblica Dominical (EBD) para a formação de valores ambientais
}

\author{
Environmental Education (EE) in non-formal spaces of education: the potential of Sunday \\ School (SS) for the formation of environmental values \\ S. E. A. $\operatorname{Costa}^{1 *} ;$ S. M. V. Castro ${ }^{2}$ \\ ${ }^{1}$ Licenciatura em Ciências Naturais-Biologia, Universidade do Estado do Pará, 66110101, Belém-Pará, Brasil \\ ${ }^{1}$ Centro de Ciências Sociais e Educação, Universidade do Estado do Pará, 66050-540, Belém-PA, Brasil
}

*s.evelynalves@gmail.com

(Recebido em 08 de abril de 2016; aceito em 05 de maio de 2016)

\begin{abstract}
Este trabalho objetivou compreender como a EBD pode contribuir para a formação de valores ambientais e de uma cidadania ambiental atuante. A metodologia adotada investigou o perfil socioeconômico e a concepção de EA e meio ambiente dos professores de EBD da Assembléia de Deus-Templo Providência localizada no bairro Maracangalha em Belém-PA através de um questionário semi-estruturado e qual relação estabelecem entre bíblia e EA por meio de entrevistas a um grupo amostral, posteriormente foi ofertado um workshop de três encontros, e por fim realizaram-se novas entrevistas com o grupo amostral buscando avaliar os resultados da ação. Constatou-se com a pesquisa que os professores, em maioria, são, mulheres, pardos, estudantes, paraenses nascidos em Belém, solteiros, frequentam a igreja em questão entre 0 e 10 anos e proferem a fé protestante pelo mesmo tempo, sendo professores voluntários da EBD pelo período de 0 á 5 anos, os sujeitos compreendem meio ambiente como um lugar para se viver e EA como a construção de ações conscientes. O grupo amostral afirmou que a bíblia discursa sobre EA e sentem-se responsáveis por fazê-la, também que o bairro onde residem não é ambientalmente cuidado. Durante o workshop, o uso de pressupostos bíblicos para a construção de uma consciência ambiental, mostrou-se positivo, despertando o interesse do público-alvo para o tema e aproximando-o de sua cultura e realidade. As entrevistas realizadas após a ação demonstraram que os participantes compreendiam melhor o tema e estavam mais dispostos a dialogar com seus alunos sobre EA, demosntrando a potencialidade da EBD.

Palavras-chave: Educação Ambiental, EBD, meio ambiente
\end{abstract}

This study aimed to understand how the SS may contribute to the formation of environmental values and an active environmental citizenship. The methodology investigated the socioeconomic profile and the conception of EE and environment of SS teachers of God-Temple Providence Assembly located in Maracangalha neighborhood in Belém-PA through a semi-structured questionnaire and what relationship established between Bible and EE through interviews with a sample group, it was posteriorly offered a workshop of three meetings, and finally took place new interviews with the sample group seeking to evaluate the results of the action. It found through research that teachers in majority, are women, brown, students, Pará born in Bethlehem, singles, attend church in question between 0 and 10 years and deliver the Protestant faith at the same time, they are volunteer teachers SS for the period from 0 to 5 years, the subjects understand environment as a place to live and EE as the construction of conscious actions. The sample group said that the Bible talks about EE and feel responsible for making her also the neighborhood where they live is not environmentally care. During the workshop, the use of biblical presuppositions to build environmental awareness, was positive, arousing the interest of the audience to the topic and approaching the culture and reality. Interviews after the action showed that the participants understand better the subject and were more willing to talk to your students about EE, demosntrando the potential of SS.

Keywords: Environmental Education, SS, environment 


\section{INTRODUÇÃO}

Com o intuito de construir um modo de pensar que sobreponha os paradigmas vigentes [1], a Educação Ambiental (EA) tem se mostrado como ferramenta para a construção de um entendimento dos valores inerentes à relação homem-natureza, a fim de auxiliar a sociedade na procura de alternativas mais acertadas para o uso dos recursos naturais, incentivando e demonstrando a relevância de ações sustentáveis para a manutenção da vida em nosso planeta.

Em acordo com a Lei Federal n 9.795, de 27 de abril de 1999 [2], a Educação Ambiental deve ser ininterrupta, frequente e permanente na educação nacional, deve nortear todos os níveis e modalidades do processo de educação: formal, que pode ser caracterizada como ações educativas desenvolvidas em espaços como o escolar; não formal, que se dá em espaços desvinculados da escola, mas que intencionam desenvolver alguma forma de ensinoaprendizagem, podendo ocorrer em praças, parques, feiras, dentre outros; e ainda informal, qualificando uma aprendizagem que ocorre em situações como um diálogo entre amigos [3].

Igrejas e locais dedicados a cultos e formação religiosa como a Escola Bíblica Dominical (EBD), reunião que se dá aos domingos de manhã em algumas igrejas protestantes na qual os participantes são organizados por faixa etária para um estudo bíblico sistemático, podem ser considerados espaços não formais de educação, os quais, de acordo coma lei acima citada, constituem um ambiente propício para a construção de uma consciência ambiental e, por conseguinte de sujeitos ecológicos ou ambientais, definidos como:

[...] agentes de mudanças, com poder e vontade de transformar a sua realidade e como sendo resultado dos processos de transformação de sua localidade, retornando a ela com o seu compromisso na construção do bemestar coletivo, consciente e ativo [4].

Acreditando que a EBD fomenta em seus alunos uma identidade religiosa e humanista significativa, a partir de seu entendimento como um espaço de cunho social e religioso [5] pressupõe-se que os valores discutidos e relacionados durante os encontros dominicais constroem o arcabouço necessário à tomada de decisões e modificação de comportamentos, propiciando um ambiente potencial para a realização de práticas de EA.

Pois, segundo Minc [6] "Educação ambiental é mudança de comportamento. Exige a combinação de elementos científicos e teóricos como experimentação, práticas e conhecimentos externos a escola", e considerando que a EA busca formar cidadãos cuja consciência crítica se reflita em filosofia de vida, e assim transforme-se em ação [7], é relevante que seja promovida em todos os grupos sociais, para que uma nova realidade socioambiental seja construída, voltada para o desenvolvimento sustentável, onde os aspectos culturais e humanos sejam agregados de tanto valor quanto os econômicos.

Mas para tanto, é preciso investigar como os grupos sociais se relacionam com as questões ambientais, dentre eles os cristãos protestantes, os quais representam cerca de $23 \%$ da população brasileira [8], e também realizar atividades de formação e conscientização em EA.

Atividades que, podem ser desenvolvidas a partir de diferentes correntes filosóficas e pressupostos epistemológicos, inclusive bíblicos, pois não obstante a realidade das necessidades socioambientais, as religiões são desafiadas a contribuir com preceitos para a formação de novos paradigmas que possibilitem a afirmação de uma sociedade sustentável, nesse contexto, a bíblia hebraica tem contribuições no sentido de promover a conscientização ambiental através de seus preceitos e valores [9].

Assim, a promoção da EA partindo de um arcabouço bíblico, poderia fornecer criativamente, pois parte de uma conjuntura pedagógica afim de um melhor entendimento sobre as temáticas que envolvem a EA [10], a fundamentação necessária para uma compreensão holística de conceitos norteadores para a fomentação de uma perspectiva ecológica.

O que conduziu ao questionamento: Como os espaços religiosos não formais de educação, como a EBD, podem contribuir para construção de valores ambientais e de uma cidadania ambiental atuante? 
Para responder a essa questão, desenvolveu-se uma pesquisa com o objetivo de compreender como a EBD pode contribuir para a formação de valores ambientais e de uma cidadania ambiental atuante e proativa.

\section{MATERIAL E MÉTODOS}

A pesquisa realizada se baseou no método de Pesquisa-Ação, onde se busca estudar a prática para que esta venha ser melhorada [11], salientando que a pesquisa-ação se destaca por ocorrer sem comprometimentos em "áreas de atuação técnico-organizativa com outros compromissos sociais e ideológicos e dá lugar em sua metodologia, a uma diversidade de propostas de pesquisa nos vários campos de atuação social" [12].

Em decorrência desse fato somou-se ao modelo de pesquisa escolhido, a concepção de pesquisa relatada por Reis, Semêdo e Gomes [13], em que Pádua e Tabanez elencam as etapas para o planejamento e execução de propostas de Educação Ambiental não formal que são: realização de diagnóstico, planejamento e execução de programa educacional e então avaliação dos resultados do trabalho.

O público-alvo da proposta foram 14 professores de EBD do templo Providência da igreja Assembleia de Deus, localizado no bairro Maracangalha, na cidade de Belém-PA, para investiga-los, utilizou-se um questionário semiestruturado de cunho socioeconômico, a fim de conhecer o perfil dos sujeitos, isso, partindo do posicionamento de que:

[...] a melhoria das condições do meio ambiente pode resultar numa melhoria das condições econômicas e sociais, pois a reciclagem de resíduos, a conservação da água e da energia são exemplos de como criar empregos e melhorar tanto a qualidade de vida da população como a qualidade do meio ambiente [14].

Pois, para desenvolver ações que envolvam a construção uma perspectiva ambiental sobre essas áreas é relevante, compreender as condições sociais e o perfil do público.

Ocorreram então, entrevistas dirigidas e gravadas a um grupo amostral de quatro professores denominados de E1 a E4, sobre o tema "Educação Ambiental e religião", e devido a esse método de coleta de informações caracterizar-se por ser um diálogo preparado com objetivos específicos [15], questões foram previamente elaboradas para auxiliar os discursos, as quais foram realizadas no começo e no fim da pesquisa, com as seguintes questões:

1) A Bíblia fala sobre Educação Ambiental, em sua concepção?

2) Como um educador, você acredita que seja responsável por fazer Educação Ambiental?

3) Você considera seu bairro ambientalmente bem cuidado?

Para a construção de conhecimentos relacionados a EA, após a coleta de dados, realizou-se um Workshop intitulado "I Workshop de capacitação de Professores de EBD: A criação proclama a glória de Deus", em três encontros em sábados consecutivos.

O primeiro encontro teve inicio com uma introdução sobre educação ambiental no contexto bíblico baseando-se em pressupostos contidos no livro de Gênesis (1.31 e 3.17-18) [16] sobre concepções de EA e meio ambiente.

Em seguida, realizaram-se as dinâmicas de grupo, "Eu pecador", a qual teve o objetivo de promover uma revisão de valores entre os participantes, para isso, foi socializado o versículo nove de I João, capítulo um, e o público foi convidado a refletir individualmente e posteriormente compartilhar com os demais, qual o seu maior "pecado ecológico" e a dinâmica "Nave Espacial", a fim de sensibilizar os participantes sobre as limitações dos recursos naturais e a importância de utilizá-los de modo sustentável, onde os professores tiveram cinco minutos para imaginar-se em uma viagem espacial, e então estabelecer cinco itens indispensáveis para sua sobrevivência, e encerrando o primeiro dia de workshop ofertou- 
se a cada professor canecas retornáveis com a logomarca do workshop, com o intuito de incentivar os professores a reduzirem o consumo de copos descartáveis.

No segundo sábado de workshop, houve uma revisão da discussão proposta no sábado anterior e foram abordados os tópicos: EA na perspectiva bíblica e EA e Cidadania, conceitos que foram discutidos com o grupo após a explanação. Após isso, foi solicitado aos participantes que formassem dois grupos e confeccionassem dois painéis com recortes de revistas, demonstrando suas compreensões a despeito dos assuntos discutidos nos dois sábados.

No decorrer do último sábado, foi exibido o vídeo: "A história das coisas", um curta metragem de 20 minutos desenvolvido pela ativista Annie Leonard em 2007, com o objetivo de demonstrar como nossa forma equivocada de lidar com o consumo afeta a natureza, e também a confecção de um puff com garrafas pet, com a finalidade de demonstrar formas de reaproveitar materiais recicláveis ao público.

O Final do Workshop foi destinado à reflexão sobre o curta assistido e a distribuição de uma cartilha aos professores sobre os temas discutidos ao longo dos três sábados.

Para a análise quantitativa dos dados obtidos com os questionários, se utilizou o método estatístico, por esse ter a finalidade de "mostrar a relação entre variáveis" [15], para tanto, foi utilizado o programa de análise estatística Excel 2010.

E para a interpretação dos dados obtidos na confecção dos painéis e com as entrevistas dirigidas pós-workshop, foi utilizado o procedimento de análise de conteúdo que se ocupa da "busca do significado de materiais textuais, sejam eles artigos de revistas, prontuários de pacientes de um hospital ou a transcrição de entrevistas realizadas com sujeitos, individual ou coletivamente" [17], para que esses dados sejam então interpretados a luz de uma teoria, no caso, sob a perspectiva da EA.

\section{RESULTADOS E DISCUSSÃO}

\section{1 Perfil dos sujeitos e da EBD}

Através da pesquisa realizada por meio dos questionários aos professores de EBD, constatou-se sobre o perfil destes que: a identidade de gênero dos participantes é predominantemente feminina (65\%), dado similar ao observado em pesquisas com professores da educação básica formal $[18,19]$, demonstrando o protagonismo histórico das mulheres na área educacional, seja ela formal ou não formal.

No tocante a faixa etária do público, a média aritmética da idade dos professores dominicais é de 38,5 anos, com predominância de mulheres entre 41 e 50 anos, se aproximando da média de 38 anos encontrada pelo Inep para professores da educação básica [19].

A maioria dos professores de EBD, 35,7\%, possui o ensino superior incompleto, ao passo que, $28,5 \%$ têm o ensino superior completo, $21,5 \%$ cursaram o ensino médio e $14,3 \%$ possuem o ensino fundamental incompleto.

Quanto à identidade de cor, a maioria declarou-se parda (78,7\%), 7,1\% afirmou ser branca, $7,1 \%$ disse ser negra e $7,1 \%$ dos entrevistados marcou a opção outro do questionário e completou dizendo ser moreno.

Cavalcanti-Schiel [20] ressalta que a identidade de cor é algo que se imputa a alguém, ou que o individuo imputa a si mesmo, por se considerar inferior ou superior. Salienta-se que "O moreno já é preconceito sem se conceber como tal, na medida em que demonstra uma autoevitação" [21], o que pode indicar a negação da identidade de cor negra, por percebê-la como sinônimo de rebaixamento e estigma social.

Averiguou-se ainda que a maior representatividade foi de indivíduos declarados, estudantes (21,5\%), naturais do Pará $(78,5 \%)$, solteiros $(53,4 \%)$, residentes de casa em alvenaria e própria $(85,7 \%)$, que passaram a proferir a fé protestante $(42,8 \%)$ nos últimos 10 anos e frequentam a igreja em questão por igual período (50\%), atuando como professores voluntaries da EBD pelo período de seis meses a cinco anos $(50 \%)$ e possuem renda entre 2 e 3 salários mínimos $(37,5 \%)$. 
No que tange a organização da EBD, há uma dirigente, uma vice dirigente e uma secretária, as quais são responsáveis pela organização da escola e também atuam como professoras substitutas de qualquer classe em casos necessários, conduzindo a composição do quadro institucional abaixo (Tabela 1).

Tabela 1 - Composição das classes dominicais.

\begin{tabular}{ccc}
\hline Faixa Etária dos Alunos & $\mathrm{N}^{\circ}$ de professores & Estilo de Classe \\
\hline 5 a 7 anos & 1 & Mista \\
7 a 10 anos & 1 & Mista \\
11 a 12 anos & 1 & Mista \\
13 a 17 anos & 3 & Mista \\
20 a 34 anos & 2 & Mista \\
30 a 40 anos & 1 & Feminina \\
40 a 68 anos & 2 & Masculina \\
Terceira Idade & 1 & Feminina \\
Todas & 3 & Mista \\
\hline
\end{tabular}

No que diz respeito a organização espacial das classes (Figura 1), estas são dispostas na nave da igreja (classes de adultos, 7 a 10 anos e 11 a 12 anos), galeria (classe de jovens), sala pedagógica (classe de 5 a 7 anos) e no salão multifuncional da igreja (classe de adolescentes), onde ocorre a reorganização dos espaços conforme as necessidades das classes.

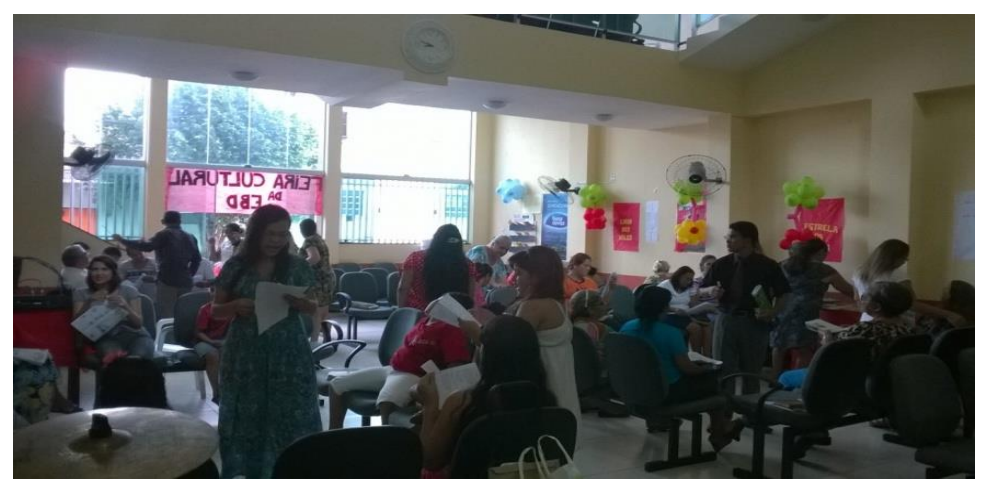

Figura 1: Organização espacial da EBD.

\subsubsection{Concepção de EA e meio ambiente}

Para se compreender melhor a relação com o ambiente vivenciada pelos professores dominicais, perguntou-se nos questionários como entendem meio ambiente e Educação Ambiental.

No tocante a ambiente, predominou $(35,7 \%)$ a concepção de que meio ambiente é o local onde vivemos e nos relacionamos com os outros seres vivos, nosso habitat, quanto a concepção de EA, 57,1\% argumentou que é preservar, reciclar, cuidar e zelar para não prejudicar a natureza e onde se vive.

A perspectiva de ambiente como habitat, de acordo com a autora Sauvé [22], se relaciona a EA na questão do cuidado com o meio ambiente incluindo a natureza e a sociedade, contribuindo para a visão de EA como uma ferramenta para mudar a realidade através de ações e práticas transformadoras, ideia que se aproxima do modo como os participantes concebem 
EA, demonstrando dessa forma como as visões entre EA e meio ambiente são assim complementares.

Segundo Reigota [23] meio ambiente, é "onde os elementos naturais e sociais estão em relações dinâmicas e em interação", ter a noção que meio ambiente é um lugar de relacionar-se, é importante por possibilitar que os indivíduos questionem como tem sido o seu relacionamento com o meio ambiente, e quais os impactos tem sido gerados por esse modo de relacionamento.

No entanto, mais que ter atitudes boas em relação ao meio que estamos inseridos, a EA prima pela construção de novos valores que direcionem essas atitudes, e que estas possam ser críticas, superando visões paradigmáticas.

\subsection{Entrevistas dirigidas pré-ação}

Durante as entrevista dirigidas, o primeiro questionamento foi "A Bíblia fala sobre Educação Ambiental, em sua concepção?". Todos afirmaram que sim, contudo, somente um dos entrevistados mencionou algum texto bíblico em sua fala, demonstrando que embora haja a consciência de que o tema se encontra nas escrituras não há uma reflexão mais profunda sobre o tema.

Sobre o questionamento, "Como um educador, você acredita que seja responsável por fazer Educação Ambiental?", houveram respostas positivas em 75\% dos casos, e um dos professores destacou que não possui completa ciência sobre suas responsabilidades quanto ao fazer EA, de acordo com a declaração subsequente:

Olha... esse tema não é tão debatido assim, não temos essa temática específica, "vamos fazer um estudo sobre Educação Ambiental dentro de uma ótica bíblica", no tempo que eu tenho de igreja pelo menos, nunca vi (E3).

Reafirmando a necessidade de ações voltadas para que as discussões sobre EA cheguem aos diferentes grupos sociais, pois, a consciência é formada a partir de um processo de reflexão e construção de valores.

Quando questionados se o bairro em que reside é bem cuidado ambientalmente, todos os entrevistados disseram que não, apontando o descarte inadequado de lixo como o principal problema ambiental.

\subsection{Execução do workshop "a criação proclama a glória de Deus"}

No primeiro sábado do workshop "A criação proclama a glória de Deus", houve a participação de 8 professores da EBD. Durante a explanação da EA sobre a ótica bíblica, na qual a criação foi apresentada como uma espécie de "Cartão de visitas de um Deus Criador", e foram citados vários versículos bíblicos a fim de compor um esboço da concepção bíblica de como gerir a natureza de forma sustentável.

O público mostrou interesse pelos temas e estava aberto a discussões e questionamentos, comportamento que se intensificou com a aplicação das dinâmicas, conduzindo a reflexões sobre a importância de pensar criticamente sobre o relacionamento que temos com a natureza, "afinal a Educação Ambiental aponta para propostas pedagógicas centradas na conscientização, desenvolvimento de competências e participação dos educandos [24]."

E essas competências que devem ser desenvolvidas não podem ser simplesmente imputadas aos indivíduos, uma vez que assim, continuariam ações inconscientes e sem valores internos duráveis.

No segundo sábado, o workshop contou com a participação de 12 professores. E ao se trabalhar a EA sendo relacionada aos princípios que envolvem a cidadania, a função do governo e das grandes empresas foi debatida pelos professores.

"Muito interessante como se nós não pressionarmos (o governo), eles não tomam atitude de cumprir o que as leis ambientais propõem" (E3 -grifo da autora).

"É as mais ricas (empresas) acabam torcendo a lei conforme lhes parece conveniente, e se a população não lutar por seus direitos, as coisas ficam como estão" (E4 -grifo da autora). 
Partindo do entendimento de natureza como um bem público [25], é necessário compreender que zelar por esse bem é dever tanto do cidadão quanto do governo, e quando a forma de uso empregada aos recursos naturais prejudicar a integridade tanto das populações quanto do meio natural, os grupos sociais precisam estar envolvidos nas decisões gestoras que podem influenciar sua qualidade de vida e de suas gerações.

Para encerrar o segundo encontro, baseado em tudo que foi discutido e construído os participantes desenvolveram dois cartazes, os quais foram expostos na igreja.

O primeiro cartaz (Figura 2) demonstra paralelamente o que é oferecido para ser consumido e o que seria consumir de forma sustentável.

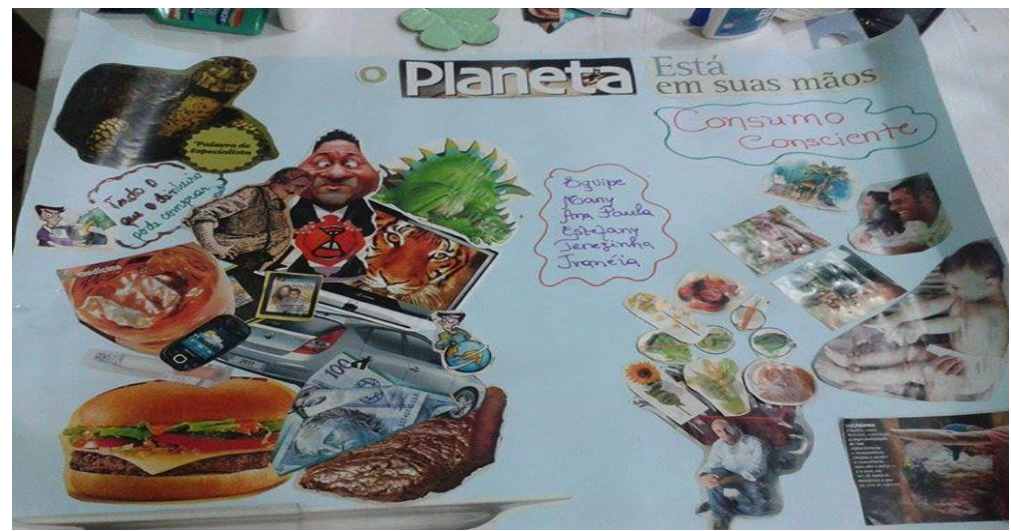

Figura 2: Cartaz "O Planeta está em suas mãos”.

Além de objetos de consumo de todo tipo, também há no cartaz as figuras de um músico e de um político, quando questionados sobre isso, um dos compositores da imagem disse que:

"A gente pode dizer que os estilos musicais, né, também é um tipo de consumo, assim como o tipo de políticos que escolhemos pra nos representar" (E2).

Esse contexto por eles evidenciado demonstra a transversalidade da educação ambiental que abrange conceitos políticos, culturais e econômicos, tornando-se assim em uma educação socioambiental, que capacita para pensar o ambiente em diversas esferas.

O segundo cartaz (Figura 3), apresenta a natureza, a criação, e cabe ao homem fazer escolhas. Essa visão que apresenta o homem como responsável por cuidar natureza, apresentou como consequência negativa das escolhas humanas, imagens de desequilíbrios ambientais, e como produto de escolhas positivas a imagem de uma família e uma de cultivo de montanha sustentável.

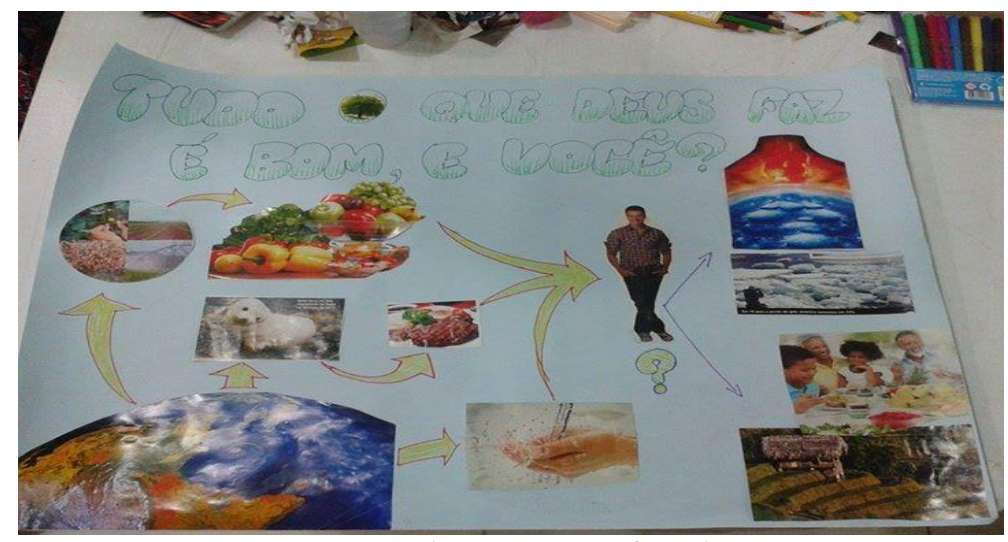

Figura 3: Cartaz “Tudo o que Deus faz é bom, e você?”.

No último e terceiro dia de Workshop, estiveram presentes 15 participantes, sendo que destes, um era aluno, demonstrando que houve um crescente interesse pela proposta. O curtametragem exibido foi discutido levantando posicionamentos sobre as etapas do consumo e a nossa relação com ele, e, além disso, propiciando a reflexão sobre as estratégias utilizadas para nos levar a consumir. 
Além da exibição do curta, ocorreu também, como uma forma de por em prática os conhecimentos obtidos e também trabalhar os conceitos de reciclagem e reutilização, além de valorizar um artigo que antes era considerado lixo, propiciou-se a construção de um puff (Figura 4) de garrafas pet, o qual após algumas indicações foi confeccionado pelos participantes.

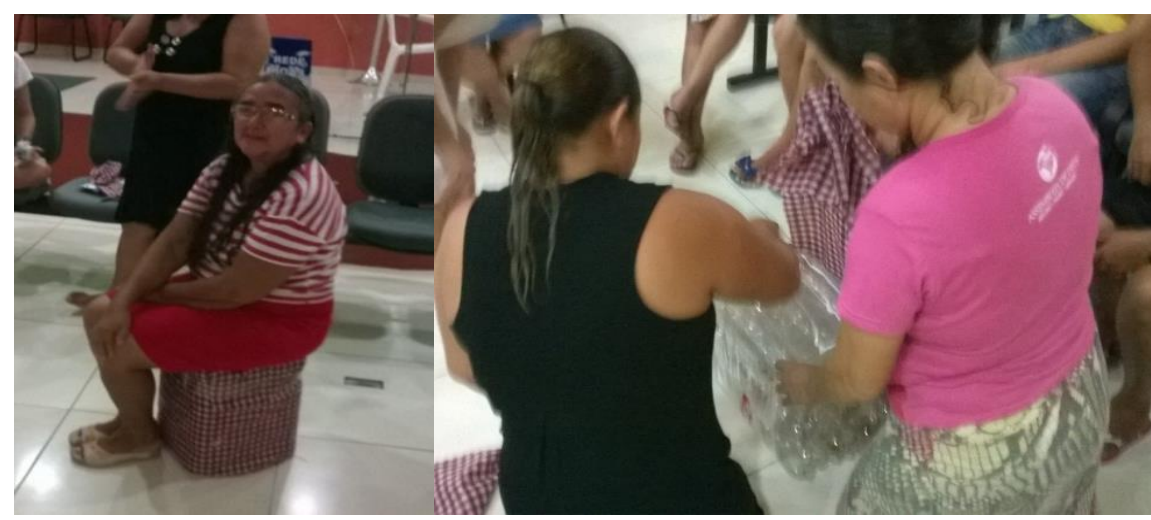

Figura 4: Confecção do Puff retornável.

Mendonça [26] discorre que do mesmo modo que o adjetivo "ambiental" veio complementar o termo educação, o termo "vivencial", completa a EA, ao propor que métodos pedagógicos e práticos que contribuam para um aprendizado real, atividades de metodologia prática, como a desenvolvida, permitem que do contato com o material, conceitos e representações venham ser construídas, para que novos modos de viver e valores sejam internalizados e transformados em prática socioambiental transformadora. Encerrando o Workshop foi entregue a cada um dos professores uma pequena cartilha que aborda alguns dos conceitos trabalhados ao longo do projeto.

\subsection{Entrevistas dirigidas pós-ação}

As entrevistas pós-ação foram realizadas dois meses após o workshop, com os mesmos sujeitos da pré-entrevista, com exceção do professor E4 que mudou-se, para assim avaliar e identificar como os professores receberam os conceitos discutidos e se estes tem sido postos em prática.

A despeito do primeiro questionamento "A Bíblia fala sobre Educação Ambiental, em sua concepção?", todos os entrevistados afirmaram que sim e exemplificaram com textos bíblicos que ressaltam a questão do cuidado com o meio ambiente e o próximo.

Para a segunda pergunta "Você como educador se sente responsável por fazer EA?". Todos os entrevistados afirmaram que sim, sentem-se responsáveis, incluindo um dos sujeitos que na entrevista pré-ação não sabia ao certo qual sua responsabilidade sobre o falar de EA.

Eu acredito que sim, porque como a gente aprendeu na palestra, o ambiente se relaciona a tudo ao nosso redor então a bíblia, ela é o maior exemplo de livro em que agente encontra noções de como podemos viver em sociedade, então eu acho que se eu não me preocupar com a EA pelo fato de achar que aquilo não vai me prejudicar, eu tenho que pensar também que pode prejudicar as próximas gerações, prejudicar uma outra pessoa (E2).

Podemos observar dessa forma, que após a prática, os participantes sentiram-se mais responsáveis em, como educadores, conscientizar seus alunos sobre o trato com o ambiente, o que certamente, nasceu das reflexões acerca das dimensões da educação ambiental propostas durante o workshop.

Uma vez que os participantes disseram que o bairro em que residem é ambientalmente mau cuidado, eles foram questionados: "Como um educador, como você acha que poderia intervir nessa questão?". Os quais replicaram que a principal forma seria por de práticas educativas e da divulgação por diferentes meios de comunicação. 
Creio que a primeira coisa a se pensar é no campo da ideologia, se entrar com a educação, divulgando, anunciando, nas ruas mesmo, eliminando o pensamento do "eu não sabia". Aí, se começarmos pela base, que é a educação, certamente teremos um bairro melhor cuidado (E3).

O proposto pelo professor E3 concorda com o recomendado por Jacobi [24], o qual defende que de fato:

Existe, portanto, a necessidade de incrementar os meios de informação e o acesso a eles, bem como o papel indutivo do poder público nos conteúdos educacionais, como caminhos possíveis para alterar o quadro atual de degradação socioambiental [24].

Socializar os saberes referentes a educação ambiental a crianças, adultos e a sociedade de forma geral, conscientizando de forma crítica e divulgando por meios de acesso social a grandes e pequenos grupos, é uma das formas de reação social contra as opressões socioambientais que nos afetam, demonstrando assim, como organizações religiosas como a EBD podem contribuir para a tão almejada cidadania ambiental atuante

\section{CONCLUSÃO}

A partir das pesquisas e ações realizadas em resposta a questão levantada nesta pesquisa sobre como a EBD poderia contribuir para a formação de valores ambientais e de uma cidadania ambiental atuante, acredita-se que na figura de seus professores, e com o uso dos princípios bíblicos para a construção de valores, a contribui a partir da socialização de saberes referentes a Educação Ambiental a sociedade de forma geral, auxiliando a formação de sujeitos conscientes de uma necessidade de mudança em sua forma de lidar e de pensar o ambiente.

Dessa forma, acredita-se que esta pesquisa contribuiu para que as práticas de educação ambiental fossem melhor difundidas em um espaço não formal de educação, a EBD, demonstrando a potencialidade do espaço e dos sujeitos que a compõem e que ainda são poucos exploradas para a formação de valores ambientais.

Assim, admite-se que a ação conseguiu aproximar conceitos desenvolvidos no âmbito da universidade com a comunidade, socializando-os e oferecendo um pouco do embasamento necessário a educadores ambientais, contribuindo para que saberes científicos, teológicos e culturais possam convergir para a promoção de melhorias sociais

\section{REFERÊNCIAS BIBLIOGRÁFICAS}

1. Guimarães M. Educação ambiental crítica. In: Layrargues PP, editor. Identidades da educação ambiental brasileira. Brasília: MMA; 2004. p. 25-34.

2. Brasil. Lei Federal $N^{\circ} 9.795$, de 27 de abril de 1999. Dispõe sobre a educação ambiental, institui a Política Nacional de Educação Ambiental e dá outras providências. Disponível em: http://www.planalto.gov.br/ccivil_03/Leis/L9795.htm. Acesso em: 2 janeiro de 2014.

3. Vieira V, Bianconi ML, Dias M. Espaços não-formais de ensino e o currículo de ciências. Cienc cult $2005 \mathrm{Dec}$ [Acesso em 15 mar 2015]; 57(4): 21-23. Disponível em: http://cienciaecultura.bvs.br/scielo.php?script=sci_arttext\&pid=S0009-67252005000400014\&lng=en.

4. Silva DV, Ferreira LA. A construção do sujeito ecológico: uma agenda contemporânea permeada pelo passado. Rev laborativa 2014 Out; 3(2): 03-20.

5. Oesselmann D, Garcia ML G. Encontros transculturais: sua importância para pensar e agir democrático de educadores (as) numa comparação internacional. Belém: Unama; 2010.

6. Minc C. Ecologia e cidadania. São Paulo: Moderna; 1997.

7. Pelicioni MCF. Educação ambiental, qualidade de vida e sustentabilidade. Saude soc. [Internet]. $1998 \mathrm{Dec} \quad$ [Acesso em 15 Jun 2015]; 7(2):19-31. Disponível em: http://www.scielo.br/scielo.php?script=sci_arttext\&pid=S0104-12901998000200003\&lng=en, doi:10.1590/S0104-12901998000200003. 
8. Instituto Brasileiro de Geografia e Estatística [homepage da internet]. Censo 2010 [Acesso em 20 out 2014]. Disponível em: http://cod.ibge.gov.br/234JG.

9. Reimer H. Textos sagrados e educação ambiental. Frag cult 2003;13(1):133- 154.

10. Reimer H. Sustentabilidade e cuidado. Contribuição de textos bíblicos para uma espiritualidade ecológica. Ciberteo 2008 Jul/Ago [Acesso em 24 nov 2013]; 18: 85-95. Disponível em: http://ciberteologia.paulinas.org.br.

11. Tripp D. Pesquisa-ação: uma introdução metodológica. Educ Pesq 2005 dez [Acesso em 15 nov 2015]; 31(3): 443-466. Disponível em: http://www.scielo.br/scielo.php?script=sci_arttext\&pid=S151797022005000300009\&lng=pt\&nrm=is o, doi: 10.1590/S1517-97022005000300009.

12. Baldissera A. Pesquisa-ação: uma metodologia do "conhecer" e do "agir" coletivo. Soc Deb 2001; 7 (2): 5-25.

13. Reis LCL, Sêmedo LTAS, Gomes RC. Conscientização ambiental: da educação formal a não formal. Rev Flum Exten Uni 2012 Jan/Jun; 2(1): 47-60.

14. Moretto CF, Schons MA. Pobreza e meio ambiente: evidências da relação entre Indicadores sociais e indicadores ambientais Nos estados brasileiros. In: Encontro da Sociedade Brasileira de Economia Ecologica: Anais do VII Encontro da Sociedade Brasileira de Economia Ecológica; 2007; Fortaleza. 2007. p. 1-20.

15. Chizzotti A. Pesquisa em ciências humanas e sociais. São Paulo: Cortez, 2006.

16. Bíblia Faithgirlz. Nova Versão Internacional. São Paulo (SP): Mundo Cristão; 2009. Gênesis 1:31, 3:17-18.

17. Appolinário F. Metodologia da ciência, filosofia e prática da pesquisa. São Paulo: Pioneira Thomson Learning, 2006.

18. Viana CP. O sexo e o gênero da docência. Cad Pagu 2001 [Acesso em: 25 set 2015]; 17-18: 81-103. Disponível em: www.scielo.br/pdf/cpa/n17-18/n17a03.pdf., doi:10.1590/S010483332002000100003 .

19. Brasil. Estudo exploratório sobre o professor brasileiro com base nos resultados do Censo Escolar da Educação Básica 2007. INEP 2009 [Acesso em: 25 set 2015]. Disponível em: http://portal.mec.gov.br/dmdocuments/estudoprofessor.pdf.

20. Cavalcanti-Schiel R. Quando nem todos os cidadãos são pardos. In: Fry P. et al. Divisões perigosas: políticas raciais no Brasil contemporâneo. Rio de Janeiro: Civilização Brasileira; 2007.p. 263-270.

21. Ribeiro AAM. No meio e misturado: o moreno como identificação de cor entre estudantes de uma escola pública. Conjec 2010 Jan/Abril [Acesso em: 24 set 2015];15 (1): 67-77. Disponivel em: HTTP://www.ucs.br/revistas/index.php/conjectura/article/download/183/174.

22. Sauvé L. Educação Ambiental e desenvolvimento sustentável: uma análise complexa. Rev Educ Públ 1997 Jul/Dez [Acesso em 26 out 2015]; 6 (10): 72-103. Disponível em: http://www.ufmt.br/revista/arquivo/rev10/educacao_ambiental_e_desenvolvim.html.

23. Reigota, M. Meio ambiente e representação social. São Paulo: Cortez, 2004.

24. Jacobi P. Educação ambiental, cidadania e sustentabilidade. Cad Pesqui 2003 mar [Acesso em 12 out 2015]; 118: 189-206. Disponivel em: http://www.scielo.br/scielo.php?script=sci_arttext\&pid=S010015742003000100008\&lng=en\&nrm=iso., dói: 10.1590/S0100-15742003000100008.

25. Quintas JS. Educação na gestão ambiental pública. In: Ferraro Júnior LA. Encontros e caminhos: formação de educadoras (es) ambientais e coletivos educadores. 2 ed. Brasília: MMA; 2007. p. 131142.

26. Mendonça R. Educação ambiental vivêncial. In: Ferraro Júnior LA. Encontros e caminhos: formação de educadoras (es) ambientais e coletivos educadores. 2 ed. Brasília: MMA; 2007.p. 117-130. 